\title{
РОЛЬ ПЕРИКРАНИАЛЬНЫХ И ШЕЙНЫХ МИОГЕННЫХ ТРИГГЕРНЫХ ЗОН В КЛИНИЧЕСКОЙ КАРТИНЕ МИГРЕНИ
}

\author{
*Р.Г.Есин, О.Р.Есин \\ Казанская государственная медицинская академия, Казань, Россия
}

Обследованы 47 пациентов с мигренью: мигрень без ауры (4 мужчины, 12 женщин), мигрень с аурой (1 мужчина, 2 женщины), сочетание мигрени и головной боли напряжения (2 мужчины, 26 женщин). У 17 пациентов обнаружены активные миогенные триггерные зоны перикраниальной и шейной локализации. Прессура этих зон вызывала типичную по локализации головную боль. У 26 пациентов обнаружены активные миогенные триггерные зоны перикраниальной и шейной локализации, которые не вызывали типичной головной боли. Лечение триггерных зон привело к уменьшению частоты и тяжести мигренозных атак на $50 \%$ у 32 пациентов. Авторы рекомендуют проводить миофасциальное тестирование пациентам с мигренью и лечение триггерных зон, если они обнаруживаются.

Ключевые слова: мигрень, миогенные триггерные зоны, лечение.

Актуальность проблемы. Мигрень - первичная хроническая повторяющаяся головная боль (ГБ) выраженной или тяжелой интенсивности, имеющая относительно высокую распространенность, отмечающаяся у $6 \%$ мужчин и 18\% женщин в США [12]. Наиболее важным клиническим проявлением мигрени являются приступы ГБ с аурой или без нее. Интенсивность ГБ, как правило, настолько высока, что нарушает повседневную активность, вынуждает прекратить ее и требует постельного режима. Тяжесть приступа обусловлена также тем, что кроме ГБ могут возникать анорексия, тошнота, фото- и фонофобия. Иногда ГБ ассоциируется с осмофобией, затуманиванием зрения, рвотой или диареей. Всемирная организация здравоохранения отнесла мигрень к наиболее инвалидизирующим заболеваниям, поражающим лиц наиболее активного возраста [7].

Патогенез мигрени в настоящее время рассматривается как мультифакториальное событие с различными комбинациями генетических и внешнесредовых факторов 1. Медицинские исследования в основном сфокусированы на механизмах возникновения ауры и генерации ГБ. Достигнуты некоторые успехи в выявлении факторов, предрасполагающих мужчин к развитию мигрени и определяющих клинические особенности заболевания. Кроме центральной нервной системы в генезе мигренозных приступов играют роль эндокринная и автономная нервная система.

Тот факт, что мигрень является пароксизмальным расстройством, запускаемым различ*e-mail: radyesin@gmail.com ными факторами, позволило главенствовать теории преодоления порога во время атаки: у пациента развивается приступ, когда преодолевается критический порог. Эта концепция подразумевает, что мигренозный приступ является результатом транзиторного или персистирующего повышения возбудимости церебральных корковых нейронов, особенно затылочной коры. Межприступное возбужденное состояние нейронов головного мозга было подтверждено транскраниальной магнитной стимуляцией и зрительной депривацией. Другим важным патогенетическим аспектом является активация тригемино-васкулярной системы [8].

Среди триггерных факторов (провокаторов) приступа мигрени рассматриваются эмоциональный стресс, мерцающий свет, изменение погоды, менструация, голод, физическое перенапряжение, нарушение режима сна и бодрствования [14]. Роль перикраниальной мускулатуры, а именно миогенных триггерных зон (МТ3) в провокации приступов мигрени изучена недостаточно, хотя имеются отдельные исследования, свидетельствующие об актуальности этого механизма активации приступа [4, 9].

Контингент пациентов и методы исследования. Целью нашего исследования явилось изучение роли МТЗ перикраниальной и шейной локализации в провокации приступов мигрени. Задачей исследования являлось изучение возможности провокации приступа мигрени прессурой МТЗ перикраниальных и шейных мышц, определение влияния устранения МТ3 
на частоту приступов мигрени.

Методы исследования включали диагностику мигрени согласно Международной классификации головной боли 2-го пересмотра [10]. Пациенты были разделены на группы: I группа - мигрень без ауры (4 мужчины, 12 женщин), II группа - мигрень с аурой (1 мужчина, 2 женщины), III группа - сочетание мигрени и головной боли напряжения (2 мужчины, 26 женщин).

Всем пациентам проводилось миофасциальное исследование с целью провокации характерной ГБ, которое включало пальпаторную диагностику и поочередную прессуру задней порции жевательной мышцы, височной мышцы, мышцы поднимающей лопатку, большой задней прямой мышцы головы, ма- лой задней прямой мышцы головы, полуостистой мышцы головы, ременной мышцы головы, ременной мышцы шеи, грудиноключичнососцевидной мышцы, трапециевидной мышцы (вертикальная и горизонтальная порции) на каждой стороне. Прессура осуществлялась интенсивным давлением до побледнения ногтевых пластинок пальцев исследователя в течение 20 секунд. Все пациенты обследованы одним исследователем.

Во время и после миофасциального исследования, пациент оценивал, провоцирует ли прессура ГБ, как в месте давления так и на расстоянии (отраженная боль). У 17 пациентов, при прессуре воспроизводилась типичная ГБ (Таблица №1).

Таблица №1

Информация о пациентах с воспроизведением типичной по локализации ГБ при прессуре МТЗ

\begin{tabular}{|c|c|c|c|c|}
\hline $\begin{array}{l}\text { Пациент № } \\
\text { по порядку }\end{array}$ & Возраст & $\begin{array}{l}\text { Длительность } \\
\text { заболевания }\end{array}$ & код по МКБ-10 & $\begin{array}{c}\text { Мышца, из которой воспроизводилась } \\
\text { типичная боль }\end{array}$ \\
\hline 1 & 48 & 10 лет & G 43.0 & жевательная мышца \\
\hline 2 & 35 & 3 года & $\mathrm{G} 43.0$ & височная мышца \\
\hline 3 & 26 & 8 лет & G 43.0 & малая задняя прямая мышца головы \\
\hline 4 & 21 & 1 год & G 43.0 & большая задняя прямая мышца головы \\
\hline 5 & 19 & 4 года & $\mathrm{G} 43.0$ & мышца поднимающая лопатку \\
\hline 6 & 52 & 15 лет & G 43+G 42.2 & полуостистая мышца головы \\
\hline 7 & 36 & 4 года & G 43+G 42.2 & $\begin{array}{l}\text { малая задняя прямая мышца головы, } \\
\text { трапециевидная мышца }\end{array}$ \\
\hline 8 & 22 & 1 год & G $43+\mathrm{G} 42.2$ & $\begin{array}{l}\text { ременная мышца головы, } \\
\text { трапециевидная мышца }\end{array}$ \\
\hline 9 & 30 & 12 лет & $\mathrm{G} 43+\mathrm{G} 42.2$ & $\begin{array}{l}\text { жевательная мышца, } \\
\text { полуостистая мышца головы }\end{array}$ \\
\hline 10 & 25 & 3 года & G 43+G 42.2 & большая задняя прямая мышца головы \\
\hline 11 & 39 & 6 лет & G 43+G 42.2 & малая задняя прямая мышца головы \\
\hline 12 & 41 & 11 лет & $\mathrm{G} 43+\mathrm{G} 42.2$ & $\begin{array}{l}\text { височная мышца } \\
\text { ременная мышца головы }\end{array}$ \\
\hline 13 & 25 & 2 года & G 43+G 42.2 & $\begin{array}{l}\text { большая задняя прямая мышца головы, } \\
\text { малая задняя прямая мышца головы }\end{array}$ \\
\hline 14 & 29 & 7 лет & $\mathrm{G} 43+\mathrm{G} 42.2$ & $\begin{array}{l}\text { жевательная мышца, } \\
\text { трапециевидная мышца }\end{array}$ \\
\hline 15 & 36 & 3 года & G 43+G 42.2 & $\begin{array}{l}\text { большая задняя прямая мышца головы, } \\
\text { малая задняя прямая мышца головы, } \\
\text { трапециевидная мышца }\end{array}$ \\
\hline 16 & 23 & 5 лет & G 43+G 42.2 & $\begin{array}{l}\text { полуостистая мышца головы, } \\
\text { ременная мышца головы }\end{array}$ \\
\hline 17 & 20 & 2 года & G $43+\mathrm{G} 42.2$ & $\begin{array}{l}\text { височная мышца, } \\
\text { большая задняя прямая мышца головы }\end{array}$ \\
\hline
\end{tabular}

Если прессура вызывала типичную ГБ, то продление прессуры более 30 секунд (обычно 1-2 минуты) приводило к уменышению интенсивнос- ти воспроизведенной ГБ. У 26 пациентов прессура вызывала локальную боль, не воспроизводящую типичную для данного ГБ (Таблица №2). 
Таблица № 2

Информация о пациентах без воспроизведения типичной по локализации ГБ при прессуре МТЗ

\begin{tabular}{|c|c|c|c|c|}
\hline $\begin{array}{l}\text { Пациент } \\
\text { № по порядку }\end{array}$ & Возраст & $\begin{array}{l}\text { Длительность } \\
\text { заболевания }\end{array}$ & код по МКБ-10 & Мышца, с наличием МТ3 \\
\hline 1 & 31 & 2 года & $\mathrm{G} 43.0$ & $\begin{array}{l}\text { большая задняя прямая мышца головы, } \\
\text { малая задняя прямая мышца головы }\end{array}$ \\
\hline 2 & 28 & 5 лет & G 43.0 & \begin{tabular}{|l} 
жевательная мышца, \\
большая задняя прямая мышца головы, \\
малая задняя прямая мышца головы
\end{tabular} \\
\hline 3 & 48 & 15 лет & G 43.0 & $\begin{array}{l}\text { жевательная мышца, } \\
\text { большая задняя прямая мышца головы, } \\
\text { полуостистая мышца головы }\end{array}$ \\
\hline 4 & 22 & 4 года & $\mathrm{G} 43.0$ & $\begin{array}{l}\text { жевательная мышца, } \\
\text { височная мышца, } \\
\text { мышца поднимающая лопатку }\end{array}$ \\
\hline 5 & 23 & 1 года & G 43.0 & $\begin{array}{l}\text { мышца поднимающая лопатку, } \\
\text { большая задняя прямая мышца головы }\end{array}$ \\
\hline 6 & 18 & 2 года & G 43.0 & $\begin{array}{l}\text { жевательная мышца, } \\
\text { ременная мышца шеи }\end{array}$ \\
\hline 7 & 52 & 10 лет & G 43.0 & $\begin{array}{l}\text { жевательная мышца, } \\
\text { большая задняя прямая мышца головы, } \\
\text { малая задняя прямая мышца головы, } \\
\text { полуостистая мышца головы }\end{array}$ \\
\hline 8 & 27 & 5 лет & G 43.0 & $\begin{array}{l}\text { жевательная мышца, } \\
\text { мышца поднимающая лопатку, } \\
\text { малая задняя прямая мышца головы }\end{array}$ \\
\hline$\overline{9}$ & 26 & 8 лет & G 43.1 & $\begin{array}{l}\text { большая задняя прямая мышца головы, } \\
\text { трапециевидная мышца }\end{array}$ \\
\hline 10 & 36 & 7 лет & G 43.1 & $\begin{array}{l}\text { большая задняя прямая мышца головы, } \\
\text { малая задняя прямая мышца головы }\end{array}$ \\
\hline 11 & 30 & 10 лет & $\begin{array}{l}\text { G } 43+ \\
\text { G } 42.2\end{array}$ & $\begin{array}{l}\text { жевательная мышца, } \\
\text { грудиноключичнососцевидная мышца, } \\
\text { малая задняя прямая мышца головы, } \\
\text { полуостистая мышца головы, } \\
\text { ременная мышца шеи, } \\
\text { трапециевидная мышца }\end{array}$ \\
\hline 12 & 26 & 3 года & $\begin{array}{l}\text { G } 43+ \\
\text { G } 42.2\end{array}$ & $\begin{array}{l}\text { мышца поднимающая лопатку, } \\
\text { большая задняя прямая мышца головы, } \\
\text { малая задняя прямая мышца головы, } \\
\text { полуостистая мышца головы, } \\
\text { трапециевидная мышца }\end{array}$ \\
\hline 13 & 18 & 3 года & $\begin{array}{l}\text { G } 43+ \\
G 42.2\end{array}$ & $\begin{array}{l}\text { грудиноключичнососцевидная мышца, } \\
\text { малая задняя прямая мышца головы, } \\
\text { ременная мышца головы, } \\
\text { трапециевидная мышца }\end{array}$ \\
\hline 14 & 52 & 20 лет & $\begin{array}{l}\text { G } 43+ \\
\text { G } 42.2\end{array}$ & $\begin{array}{l}\text { большая задняя прямая мышца головы, } \\
\text { полуостистая мышца головы, } \\
\text { трапециевидная мышца }\end{array}$ \\
\hline 15 & 33 & 5 лет & $\begin{array}{l}\text { G } 43+ \\
\text { G } 42.2\end{array}$ & $\begin{array}{l}\text { жевательная мышца, } \\
\text { мышца поднимающая лопатку, } \\
\text { большая задняя прямая мышца головы, } \\
\text { малая задняя прямая мышца головы, } \\
\text { полуостистая мышца головы, } \\
\text { ременная мышца головы, } \\
\text { трапециевидная мышца }\end{array}$ \\
\hline
\end{tabular}


Таблица № 2 (продолжение) Информация о пациентах без воспроизведения типичной по локализации ГБ при прессуре МТЗ

\begin{tabular}{|c|c|c|c|c|}
\hline 16 & 37 & 2 года & $\begin{array}{l}\mathrm{G} \text { 43+ } \\
\mathrm{G} \text { 42.2 }\end{array}$ & $\begin{array}{l}\text { мышца поднимающая лопатку, } \\
\text { грудиноключичнососцевидная мышца, } \\
\text { малая задняя прямая мышца головы, } \\
\text { полуостистая мышца головы, } \\
\text { трапециевидная мышца }\end{array}$ \\
\hline 17 & 45 & 10 лет & $\begin{array}{l}\mathrm{G} \text { 43+ } \\
\mathrm{G} 42.2\end{array}$ & $\begin{array}{l}\text { височная мышца, } \\
\text { большая задняя прямая мышца головы, } \\
\text { малая задняя прямая мышца головы, } \\
\text { полуостистая мышца головы, } \\
\text { ременная мышца головы, } \\
\text { трапециевидная мышца }\end{array}$ \\
\hline 18 & 22 & 2 года & $\begin{array}{l}\text { G } 43+ \\
\text { G } 42.2\end{array}$ & $\begin{array}{l}\text { малая задняя прямая мышца головы, } \\
\text { полуостистая мышца головы, } \\
\text { трапециевидная мышца }\end{array}$ \\
\hline 19 & 18 & 2 года & $\begin{array}{l}\text { G } 43+ \\
\text { G } 42.2\end{array}$ & $\begin{array}{l}\text { большая задняя прямая мышца головы, } \\
\text { малая задняя прямая мышца головы, } \\
\text { полуостистая мышца головы, } \\
\text { трапециевидная мышца }\end{array}$ \\
\hline 20 & 29 & 5 лет & $\begin{array}{l}\mathrm{G} \text { 43+ } \\
\mathrm{G} 42.2\end{array}$ & $\begin{array}{l}\text { жевательная мышца, } \\
\text { малая задняя прямая мышца головы, } \\
\text { полуостистая мышца головы, } \\
\text { ременная мышца шеи, } \\
\text { трапециевидная мышца }\end{array}$ \\
\hline 21 & 36 & 4 года & $\begin{array}{l}\text { G } 43+ \\
\text { G } 42.2\end{array}$ & $\begin{array}{l}\text { жевательная мышца, } \\
\text { грудиноключичнососцевидная мышца, } \\
\text { большая задняя прямая мышца головы, } \\
\text { полуостистая мышца головы, } \\
\text { ременная мышца головы, } \\
\text { трапециевидная мышца }\end{array}$ \\
\hline 22 & 41 & 13 лет & $\begin{array}{l}\mathrm{G} \text { 43+ } \\
\mathrm{G} 42.2\end{array}$ & $\begin{array}{l}\text { височная мышца, } \\
\text { полуостистая мышца головы, } \\
\text { ременная мышца шеи, } \\
\text { трапециевидная мышца }\end{array}$ \\
\hline 23 & 44 & 4 года & 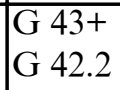 & $\begin{array}{l}\text { полуостистая мышца головы, } \\
\text { ременная мышца головы }\end{array}$ \\
\hline 24 & 18 & 2 года & $\begin{array}{l}\text { G } 43+ \\
\text { G } 42.2\end{array}$ & $\begin{array}{l}\text { полуостистая мышца головы, } \\
\text { ременная мышца головы, } \\
\text { трапециевидная мышца }\end{array}$ \\
\hline 25 & 28 & 10 лет & $\begin{array}{l}\text { G } 43+ \\
\text { G } 42.2\end{array}$ & $\begin{array}{l}\text { грудиноключичнососцевидная мышца, } \\
\text { большая задняя прямая мышца головы, } \\
\text { полуостистая мышца головы, } \\
\text { ременная мышца головы, } \\
\text { ременная мышца шеи, } \\
\text { трапециевидная мышца }\end{array}$ \\
\hline 26 & 48 & 18 лет & $\begin{array}{l}\mathrm{G} \text { 43+ } \\
\mathrm{G} 42.2\end{array}$ & $\begin{array}{l}\text { большая задняя прямая мышца головы, } \\
\text { ременная мышца головы, } \\
\text { трапециевидная мышца }\end{array}$ \\
\hline
\end{tabular}

Наиболее часто активные МТЗ располагались в трапециевидной мышце, большой задней прямой мышце головы, малой задней прямой мышце головы и полуостистой.

Только у 2-х пациентов, страдавших мигренью без ауры, не были обнаружены МТЗ. Этим пациентам была назначена лекарственная терапия согласно рекомендациям Европейской федерации неврологических обществ [2].

Все пациенты вели дневник головной боли [6] в течение 2 месяцев до лечения и 6 месяцев после начала лечения. 
При наличии активных МТЗ центральная сенситизация, проявляющаяся аллодинией и гипералгезией, затрудняет мануальное лечение. Пациентам назначались аналгетики центрального действия (тизанидин 2-12 мг в сутки или флупиртин 300-600 мг в сутки) на 30 дней с целью купирования проявлений центральной сенситизации для облегчения мануального лечения.

Тревожное расстройство диагностировано у 12 (75\%) пациентов I группы, 2 (66,6\%) пациентов II группы, 20 (71,4\%) пациентов III группы. Этим пациентам назначался растительный транквилизатор, состоящий из комбинации патентованных сухих экстрактов растения Valeriana officinalis (корень Валерианы - WS® 1014 (160 мг) и растения Melissa officinalis (листья Мелиссы WS® 1303 (80 мг) - Дормиплант по 1 таблетке два раза в день в течение 2-х недель.

При уменьшении симптомов центральной сенситизации и тревоги начинали мануальное лечение, заключавшееся в проведении постизометрической релаксации мышщ, прессуре [11], либо назначалась фитнес-программа при наличии приверженности пациентов этому методу лечения.

Пациенты повторно осматривались каждые 14 дней в течение первых 3 месяцев, затем каждый месяц на протяжении полугода. Пациенты сообщали об уменьшение частоты эпизодов и выраженности головной боли, а так же уменьшение тошноты, рвоты, фото- и фонофобии.

Результаты. Исходный уровень интенсивности ГБ в группе I по ВАШ составлял $90 \pm 5,17$ мм. Через 2 месяца на фоне проводимой терапии интенсивность ГБ составила

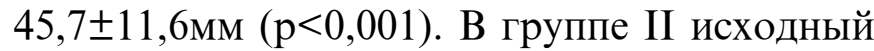
уровень ГБ по ВАШ 88,3 $\pm 6,24 \mathrm{Mм}$, после лече-

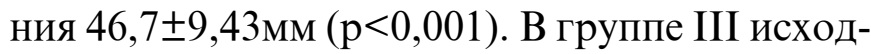

\section{ЛИТЕРАТУРА}

1. Табеева Г.Р., Яхно Н.Н. Мигрень: монография. М: ГЭОТАР-Медиа 2011; С. 327-328.

2. Evers S., Afra J., Frese A. et al. EFNS guideline on the drug treatment of migraine - revised report of an EFNS task force. European Journal of Neurology 2009; 16: 968-981.

3. Fernandez-de-las-Penas C., Cuadrado ML., Arendt-Nielsen L. et al. Myofascial trigger points and sensitization: an updated pain model for tensiontype headache. Cephalalgia 2007; 27(5): 383-393.

4. Fernandez-de-Las-Penas C., Simons D., Cuadrado ML. et al. The role of myofascial trigger points in mus-

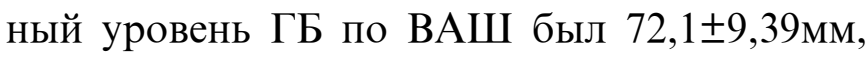

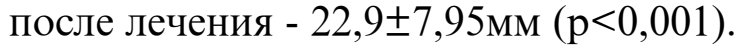

Положительный эффект лечения, выражающийся в уменьшении частоты дней с головной болью на $50 \%$ и более в группе I отметили 10 пациентов (71\%), в группе II - 2 пациента (66\%), в группе III - 22 пациента (79\%).

Обсуждение результатов. В настоящее время имеются немногочисленные данные о том, что МТЗ могут вызывать центральную сенситизацию и тем самым играть важную роль в оформлении клинической картины головной боли напряжения 3,5. Экспериментальны исследования показали, что стимуляция глубоких отделов мышщ более эффективно индуцирует центральную сенситизацию, чем стимуляция кожи 13,15. Основываясь на обнаруженных нами клинических фактах, можно сказать, что пациенты с различными формами мигрени могут иметь активные МТЗ шеи и головы. Уменьшение частоты и интенсивности мигренозных атак после устранения МТЗ позволяет сделать вывод о том, что миогенный компонент играет важную роль в развитие мигрени, вероятно, за счет сенситизации нейронов тригеминоваскулярной системы.

\section{Выводы:}

1. Исследование перикраниальных и шейных мышц у пациентов с клинической картиной мигрени является важным пунктом клинического обследования.

2. Устранение перикраниальных и шейных МТЗ позволяет значительно снизить частоту и тяжесть мигренозных атак у большей части пациентов.

3. Профилактика формирования МТ3 шейной и перикраниальной локализации является важным пунктом профилактики приступов мигрени.

culoskeletal pain syndromes of the head and neck. Current Pain and Headache Reports 2007; 11: 365-372. 5. Giamberardino M.A., Tafuri E., Savini A. et al. Contribution of myofascial trigger points to migraine symptoms. J Pain 2007; 8(11): 869-78.

6. Headache Diary. Available at: http://uhs.berkeley.edu/home/healthtopics/pdf/diary.pdf

7. Menken M., Munsat TL., Toole J.F. The global burden of disease study: implications for neurology. Archives of Neurology 2000; 57(3): 418-420.

8. Mehta N.R., Maloney G.E., Bana D.S. et al. Head, 
Face and Neck Pain: Science, Evaluation, and Management. An Interdisciplinary Approach. A John Wiley \& Sons Inc. Publication 2009; P. 108-130. 9. Sorrell M. Myofascial Examination Leads to Diagnosis and Successful Treatment of Migraine Headache. Journal of Musculoskeletal Pain 2010; 18(1): P. 32-37. 10. The International Classification Of Headache Disorders 2nd Edition. Cephalalgia 2004; 24 (Suppl. 1): P. 1-150.

11. Travell J.G., Simons D.G. Myofascial Pain and Dysfunction. The Trigger Point Manual. BaltimoreLondon: Williams \& Wilkins 1983; 713 p.

12. Stewart W.F., Lipton R.B., Celentano D.D. et al.
Prevalence of migraine headache in the United States. Relation to age, income, race, and other sociodemographic factors. JAMA 1992; 267(1): P. 64-69.

13. Wall P.D., Woolf C.J. Muscle but not cutaneous $\mathrm{C}$-afferent input produces prolonged increases in the excitability of the flexion reflex in the rat. The Journal of Physiology 1984; 356: P. 443-458.

14. Wober C., Holzhammer J., Zeitlhofer J. et al. Trigger factors of migraine and tension-type headache: experience and knowledge of the patients. The Journal of Headache and Pain 2006; 7: P. 188-195.

15. Woolf C J. Windup and central sensitization are not equivalent. J Pain 1996; 66: P. 105-108.

\title{
SUMMARY
}

\section{ROLE OF TRIGGER POINTS IN PERICRANIAL AND CERVICAL MUSCLES IN MIGRAINE CLINICAL PRESENTATION}

\author{
R.G.Esin, O.R.Esin \\ Kazan State Medical Academy, Kazan, Russia
}

We examined 47 migrainous patients: migraine without aura (4 male, 12 female), migraine with aura ( 1 male, 2 female), migraine in combination with tension-type headache ( 2 male, 26 female). 17 patients had active muscle trigger points in pericranial and neck muscles. The pressure of these points caused typical headache. 26 patients had active muscle trigger points in pericranial and neck muscles and the pressure of these points didn't cause typical headache. The treatment of muscle trigger points resulted in frequency reduction and burden of migraine attacks to $50 \%$ and more of 32 patients. Authors recommend providing myofascial examination in migrainous patients and treating trigger points if they are found.

Key words: migraine, muscle trigger points, treatment.

\section{XÜLASə \\ MIQQRENIN KLINIKİ MONZəRəSINDӘ PERÍKRANIAL VӘ BOYUN MIOGEN TRIGGER NÖQTOLORININ ROLU}

\author{
R.Q.Yesin, O.R.Yesin \\ Kazan Dövlat Tibb Akademiyası, Kazan, Rusiya
}

47 miqrenli xəstə müayinə edilmişdir: aurasız miqren (4 kişi, 12 qadın), auralı miqren (1 kişi, 2 qadın), miqren və gərginlik baş ağrılarının müştərək olması (2 kişi, 26 qadın). 17 xəstədə perikranial və boyun lokalizasiyalı aktiv miogen trigger zonaları aşkar edilmişdir. Bu zonaların pressurası lokalizasiyasına görə tipik baş ağrı törətmişdir. 26 xəstədə tipik baş ağrı verməyən perikranial və boyun lokalizasiyalı aktiv miogen trigger zonaları aşkar edilmişdir. 32 xəstədə trigger zonaların müalicəsi miqrenoz həmlələrin tezliyinin və ağırlığının $50 \%$ azalmasına səbəb olmuşdur. Müəlliflər miqrenli xəstələrin miofassial müayinəsini aparmağı və trigger zonalarının müalicəsini (əgər aşkarlanırsa) tövisyə edirlər.

Açar sözlər: miqren, miogen trigger zonalar, müalicə.

Redaksiyaya daxil olub: 08.07.2013

Çapa tövsiya olunub: 03.08.2013

Rayçi: X.I.Hasanov, t.ü.f.d. 